\title{
Editorial
}

\section{Wonderful Plants: The Continuing Evolution of Homeopathy}

\author{
Sally Williams ${ }^{1}$ \\ 1 United States \\ Homœopathic Links 2017;30(2):71.
}

In 1996, Jan Scholten was invited by Lou Klein to give a seminar on his Element Theory in Boston, Massachusetts. At that time, I had only been practicing homeopathy for 4 years and had never heard of Jan or the Element Theory. Jan's presentation was brilliant, fascinating and daunting. Trying to wrap my head around the stages and series, understanding where the problem lies, how confident a person was, was the patient on the right or the left side of the periodic table and how a salt could make the prescription more precise was all very intimidating! I never thought I would be able to understand the system, let alone apply it successfully. Now 21 years later it has become second nature to me. It is a fundamental component of my approach to cases and I think in stages and series for every case I take.

Over the next 15 years, Jan would introduce the Lanthanides and began to develop and teach his understanding of plants and plant families. In October 2012, Jan introduced his Plant Theory to North America at a seminar in Toronto, Ontario. I was left with many of the same feelings I had 16 years prior. Once again, I was amazed and intimidated! I knew, however, that this was the next evolutionary step for homeopathy and became focused on learning the system. I started to attend his plant seminars every May in Utrecht, the Netherlands, assisted in editing 'Wonderful Plants', and in February 2016 organised a plant proving seminar in Bocas Del Toro, Panama, for a group of 15, including Jan and Robert Muntz, Mag. Pharm at Remedia Homeopathic Pharmacy in Eisenstadt, Austria.

In this issue of LINKS, we are excited to present Jan's Plant Theory, some of the fruits of our provings in Panama, and to share with you the sweet success of accurately prescribed remedies we could have never arrived at in any other way. We invite you to consider exploring the advantages of employing Jan's Plant Theory in your practice and to experience the joy of uncovering the eternally unfolding depths of homeopathy once again. I have told Jan many times that the Plant Theory has made homeopathy as exciting for me as it was when I first learned of it

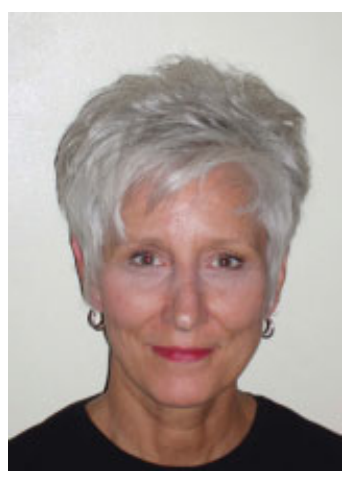

Sally Williams 30 years ago. The result of curing a case with a plant unknown to you-while also understanding the nature and depth of that single plant and its relationship homeopathically, botanically and chemically-is profoundly gratifying.

Jan's Plant Theory provides a scientific, systematic approach to the homeopathic application of the plant kingdom, and it also validates the science of homeopathy by utilising the universally proven and accepted sciences of chemistry and botany. Even though the thought of learning and applying the Plant Theory may seem overwhelming (and it can be), the fact that it is built upon established integrated systems makes it possible. Jan will be the first one to tell you it is a work in progress and by no means complete. Because the theory is still in its formative years, it allows us all the opportunity through our own working experiences, to contribute to its evolution. Jan invites you to visit his Web site www.qjure.com and participate in the discovery, application and continuing development of the Plant Theory.

My experience with the Plant Theory has been both exhilarating and frustrating. It is once again like the Element Theory, a bit of a task to learn and master and I am nowhere near mastering it, but the journey in and of itself is the reward. I have been more accurate in prescribing plants than I have ever been in my 25 years of practice, and therefore helping more patients. The incredible joys of the science of homeopathy have been ignited once again!

I sincerely hope you enjoy and are inspired by this issue of Links!!
Address for correspondence Sally Williams, RSHom(NA), CCH, 524 Rhode Island St., Buffalo, NY 14213, United States (e-mail: SAWRSHOM@msn.com). (c) 2017 Thieme Medical and Scientific Publishers Private Ltd.
DOI https://doi.org/ 10.1055/s-0037-1602779. ISSN 1019-2050. 